\title{
Working
}

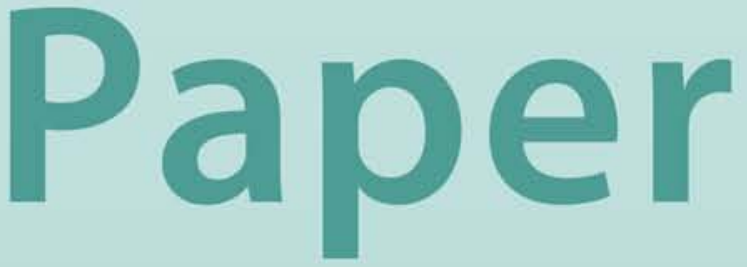




\title{
Pricing Fund Liquidity Provision
}

\author{
Marco Rossi
}




\title{
IMF Working Paper
}

\author{
European Department
}

\section{Pricing Fund Liquidity Provision}

\section{Prepared by Marco Rossi ${ }^{1}$}

Authorized for distribution by Emmanuel van der Mensbrugghe

February 2007

\begin{abstract}

\section{This Working Paper should not be reported as representing the views of the IMF.}

The views expressed in this Working Paper are those of the author(s) and do not necessarily represent those of the IMF or IMF policy. Working Papers describe research in progress by the author(s) and are published to elicit comments and to further debate.

This paper presents a market-based framework for pricing Fund liquidity assistance that accounts for the credit risk and the insurance benefit involved in such operations. It is based on the isomorphic correspondence between Fund liquidity and common stock put options. Although only illustrative, the simulations presented in this paper show that the value of the liquidity guarantee provided by the Fund could range from a few to over one hundred basis points depending on the borrower's creditworthiness, the volatility of capital flows to the borrowing country, and the amount of funds potentially needed to meet the borrower's external obligations.

JEL Classification Numbers:F33, F34, F53, G13.

Keywords: Fund financing facility, lender of last resort, liquidity provision, option pricing. Author’s E-Mail Address:

\footnotetext{
${ }^{1}$ The author would like to thank Peter Breur, Ulric Erickson von Allmen, Brett House, Francesco Luna, Ousmene Mandeng, Alan MacArthur, Michael Pedroni, Roberto Perrelli, Sebastian Sosa, Andrew Tweedie for helpful comments. The usual disclaimer applies.
} 


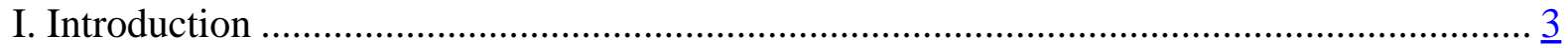

II. A Pricing Framework for a Liquidity Facility ..................................................... 4

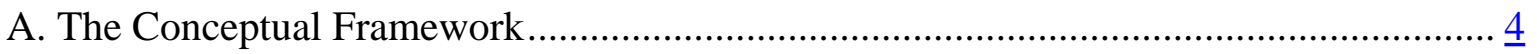

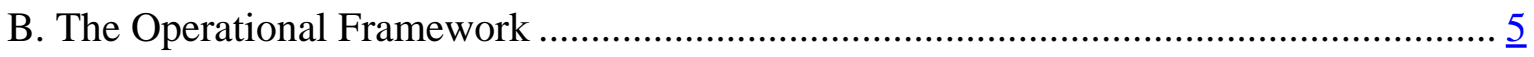

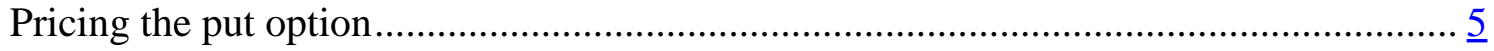

Assessing the probability of no access to markets .................................................. $\underline{7}$

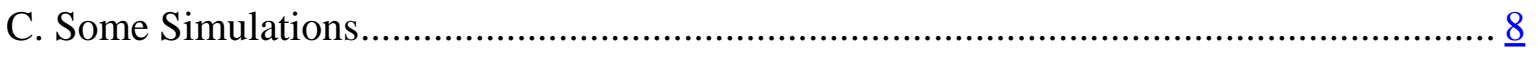

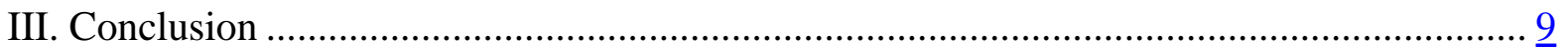

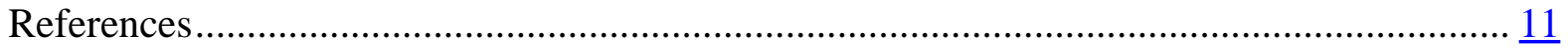




\section{INTRODUCTION}

A number of member countries has called for a new Fund financing instrument specifically designed to support crisis prevention in countries with access to international capital markets. As part of the Fund's Medium-Term Strategy, a new vehicle for the provision of high access financing is being considered. The goal is to create a new instrument that (i) is predictable in terms of funds availability; (ii) would provide enough liquidity to minimize the risk of a crisis, (iii) would address concerns about the signaling effect of acceding the facility, (iv) would provide adequate safeguards for the use of Fund resources without excessive conditionality, and (v) would minimize the moral hazard and reputational risks to the Fund.

Under discussion is the Reserve Augmentation Line (RAL). Its main features currently are: (a) qualification upon request and subject to strong macroeconomic policies, sustainable debt, transparent reporting, and progress in addressing vulnerabilities to shocks; (b) periodic monitoring of policy implementation by staff; (c) available financing up to 300 percent of quota; (d) same charges and maturities structure as the Supplement Reserve Facility; and (e) immediate availability of funds for those member countries that have met program monitoring objectives.

Pricing is one key aspect in the design of any financing instrument, including the RAL, as it could attain several of the goals that the instrument is expected to achieve and in a market-based manner. Under current Fund facilities, except for the Poverty Reduction and Growth Facility, purchasing members are assessed the basic rate of charge, which is equal to the SDR interest rate plus a margin - currently set at about 108 basis points. The rate of charge is additionally modified to incorporate burden sharing adjustments and the financial consequences of protracted arrears. The average adjusted basic rate of charge over the last quarter was about 120 basis points above the SDR interest rate. A surcharge applies to specific facilities, as do service and commitment charges.

While these fees are intended to recoup administrative and opportunity costs and to build precautionary balances, they do not explicitly incorporate an assessment of the borrower's credit risk, and, in the case of the RAL, the intrinsic value of the liquidity guarantee that it provides to the borrower. ${ }^{2}$ To be sure, the margin, and the surcharge in cases of high access levels, may help incorporate these risks/benefits, but rather non transparently and only ex post, that is, once the purchase has been made. Moreover, in situations of incomplete information, a fixed fee or a fee increasing in the amount or the term of the credit are not completely satisfactory either because it is difficult to ascertain its right (in economic terms) level without creating distortions in the market or because of moral hazard and adverse selection. Whenever charges either do not function as disincentive for a borrower to become over leveraged or increase the likelihood that only countries with high non-observable risk borrow, a simple pricing formula may achieve an increase, rather than a reduction, in the credit risk sustained by the Fund.

\footnotetext{
${ }^{2}$ The Fund's preferred creditor status is often mentioned to weaken the rationale for formally assessing credit risk. However, pricing such a risk would help restore a proper ex ante incentive structure to borrow and foster the implementation of policies that would minimize the chances of having to receive Fund financing assistance.
} 
This paper proposes a market-based framework for pricing Fund liquidity provision that explicitly distinguishes between lower- and higher-risk borrowers, while incorporating the benefits to the borrower of being able to tap a source of liquidity when necessary. While the framework is general, it can be used to price liquidity provision under the RAL. The framework is based on the isomorphic correspondence between Fund liquidity and common stock put options. The fees generated by this framework would complement the SDR interest rate, plus adjustments and service and commitment charges, and would be assessed upfront at time of qualification. While distinguishing between lower- and higher-risk borrowers would raise concerns about equality of treatment across the membership-a principle that is at the core of the Fund's mandate-there might be ways to address these concerns operationally.

\section{A Pricing Framework For a LIQUidity FaCILITY}

\section{A. The Conceptual Framework}

A member country seeks to qualify for access to Fund liquidity, which is extended for a year. ${ }^{3}$ At the time of qualification, the amount of the country's net external obligations, (D), over the following year-net short-term debt by residual maturity-is known. ${ }^{4}$ These obligations can be met by using the country's stock of international reserves (R) and/or accessing the international capital markets (MF). ${ }^{5}$

A country's liquidity position (L) can therefore be defined as:

$$
\mathrm{L}=\mathrm{R}+\mathrm{MF}
$$

whose level and fluctuations depend on the behavior of R and MF over time.

The level of a country's reserves is affected by the flows in its balance of payments as well as changes in its residents' currency preferences, which are both stochastic. R can be described by a geometric Brownian motion:

$$
d \mathrm{R}=\mu \mathrm{R} d t+\sigma \mathrm{R} d z
$$

where $d z$ is a Wiener process, implying a log-normal distribution for $\mathrm{R}$.

Access to capital markets depends on the country's perceived ability to continue meeting its obligations. At any point in time, a country may or may not rely on market financing to

\footnotetext{
${ }^{3}$ Under the RAL current proposal, a member's access would be reviewed twice a year.

${ }^{4}$ Clearly a country's liquidity requirements may exceed its net short-term debt in a crisis situation when capital flight is likely. D would then need to be defined in practice on a case-by-case basis, including by taking the country's financial structure and degree of dollarization into account.

${ }^{5}$ Market financing (MF) would include syndicated loans and Eurobond placements.
} 
complement its international reserve position to service its obligations. MF can therefore be described by a stationary binomial stochastic process:

$$
\mathrm{MF}=(>0 \text {, with probability q; } 0 \text {, with probability 1-q) }
$$

with $\mathrm{q}$ as the probability of being solvent or liquid. ${ }^{6}$

By qualifying for Fund liquidity, a member would be able to obtain additional liquidity—that is, in addition to its current level of reserves - in the case of a reversal of market sentiments-i.e. $M F=0$. The value of this liquidity guarantee to the member is: ${ }^{7}$

$$
\begin{aligned}
\mathrm{V} & =[\max (\mathrm{D}-\mathrm{R}, 0)] \text { prob (no access to capital markets) } \\
& =[\max (\mathrm{D}-\mathrm{R}, 0)](1-\mathrm{q})
\end{aligned}
$$

The first term in (4) is akin to the payoff of a put option, where the amount of international reserves, $\mathrm{R}$, is the stock price and the amount of debt service, $\mathrm{D}$, is the strike price. By qualifying a member country for access to liquidity (including under the RAL), the Fund would be writing a (notional) put option on the member's liquidity. By exercising the option, the member country would obtain a cash inflow in the case its liquidity falls short of its short-term obligations, that is, in a situation in which other sources of external borrowing cannot be accessed.

As for any insurance contract, the value of the guarantee should be, at least, equal to the cost imposed on the guarantor. Its value, contingent on the member country's access to international capital markets, could therefore represent the cost to the Fund of providing this particular service to its membership. To be sure, this is the cost of only the guarantee element of providing liquidity, that is, of the benefit to a member. The other costs to the Fund are already included in the adjusted rate of charge, and service and commitment fees.

\section{B. The Operational Framework}

From an operational viewpoint, pricing Fund liquidity would entail pricing the put option and assessing the probability of no access to capital markets for a qualifying member country.

\section{Pricing the put option}

Calculating the option premium depends on the type of option being written. Access to Fund liquidity over the lifespan of the instrument under which the liquidity is provided could be

\footnotetext{
${ }^{6}$ In today's liquid markets, a distinction between solvency and liquidity is increasingly blurred. In fact, a borrower that is perceived as solvent based on some present value calculations of its stock of debt may still be denied normal access to capital markets should its liquidity requirements in the short term appear hard to meet to its potential creditors.

${ }^{7}$ If solvency and liquidity were related but separate concepts, an additional correlation term would need to be added to (4).
} 
allowed (i) once to coincide with its expiration, (ii) a discrete number of times, or (iii) at any point in time. The option would, respectively, be a European, Bermudan, or American and its valuation present increasing complexity. ${ }^{8}$

\section{European option}

The value of the put option or the cost of the liquidity guarantee, according to the Black and Scholes formula, would be:

$$
\mathrm{V}(\tau)=(1-\mathrm{q})\left[\mathrm{D} e^{-r \tau} \mathrm{N}\left(d_{2}\right)-\mathrm{R} N\left(d_{1}\right)\right]
$$

where: $d_{1}=\frac{1}{\sigma \sqrt{\tau}}\left[\ln \frac{D}{R}-\left(r+\frac{\sigma^{2}}{2}\right) \tau\right]$

$d_{2}=d_{1}+\sigma \sqrt{\tau}$

$\sigma^{2}$ is the variance rate per unit of time for the logarithmic change in the value of $\mathrm{R}$

$r$ is the discount factor

$\tau$ is the maturity of the option contract

$\mathrm{N}\left(d_{i}\right)$ is the cumulative normal density function.

Per unit of external obligations, D, this could be expressed as:

$$
\mathrm{v}(\tau)=(1-\mathrm{q})\left[\mathrm{N}\left(x_{2}\right)-1 / d \mathrm{~N}\left(x_{1}\right)\right]
$$

where: $x_{1}=\frac{1}{\sigma \sqrt{\tau}}\left[\ln d-\sigma^{2} \tau\right]$

$$
x_{2}=x_{1}+\sigma \sqrt{\tau}
$$

$\sigma^{2} \tau$ is the variance of the logarithmic change in the value of R during the term of the Fund facility

$$
d=\frac{D e^{-r \tau}}{R}
$$

Equation (5) shows that the value of the option depends on the amount of the liquidity that would be accessible if the option is exercised, the maturity of the liquidity guarantee, and the volatility of the member country's liquidity. These relations apply to all option types, despite

\footnotetext{
${ }^{8}$ A premium is attached to the privilege of early exercise provided by Bermudan and American options, which is reflected in the value of a European option being not greater than those of the other types.
} 
their pricing involves different numerical and analytical procedures. Specifically, the value of the option increases in each of these variables:

$$
\begin{aligned}
& \frac{\partial v}{\partial d}=\frac{N\left(x_{1}\right)}{d^{2}} \\
& \frac{\partial v}{\partial \tau}=\frac{N^{\prime}\left(x_{1}\right)}{2 d \sqrt{\tau}}
\end{aligned}
$$

where $\mathrm{N}^{\prime}\left(x_{1}\right)$ is the first derivative of the cumulative normal density function $\mathrm{N}\left(x_{1}\right)$. An increase in the volatility of a country's liquidity position increases the value of the liquidity guarantee since a country with more volatile foreign exchange flows is more likely to remain illiquid in case of an exogenous shock.

It is worth noting that changes in the market rate of interest (discount factor) does not have an impact on the value of the guarantee, unless they impact $d$. A higher discount rate, in fact, would increase the opportunity cost of holding reserves (hence reducing their precautionary level), but, at the same time, it would reduce the present value of the external obligations to be repaid by the end of the year, hence reducing the expected payoff of the option.

\section{Bermudan and American options}

The freedom to exercise the option at specific times or at any time introduces a boundary problem to solving the differential equation in an option pricing model. No exact pricing formula, like Black-Scholes', exists; numerical procedures and analytic approximations are instead used.

The binomial option pricing model provides a numerical method that mimics the behavior of the underlying instrument - in our case the member country's liquidity position-over time. In each short interval of time, the value of the underlying instrument is assumed to move up or down by a certain amount and with a certain probability so that its mean and standard deviation conform with a risk-neutral environment. The option is then priced by calculating the value of the option at expiration and working backwards along the tree. Finite difference methods work similarly, converting the underlying differential equation into a difference equation. MacMillan (1986) and Barone-Adesi and Whaley (1987) propose an analytic approximation for the valuation of an American option based on estimating the difference between European and American option prices. Software is available to calculate option prices on the basis of these numerical and analytic methodologies.

\section{Assessing the probability of no access to markets}

An assessment of a member country's probability to have access to international capital markets seriously curtailed at some point in time can be proxied by a number of indicators. Early warning systems, ratings transition matrices, implied probability of default embedded in derivative assets prices_credit default swaps, currency and sovereign debt options, for instance-and financial indicators on financial risks and stability—such as the expected number 
of defaults, the distance to default. One or more of these proxies are usually available or could be constructed for each member country with access to international capital markets.

While a summary index to reflect market perceptions of a country's ability to borrow can then be derived from available proxies, it should be noted that the value of such an index would typically be small, reflecting the fact that Fund liquidity provision, particularly under the RAL, would be targeted to those countries that are vulnerable, but are implementing, at the time of qualification, sustainable policies.

\section{Some Simulations}

Below are some illustrative simulations to show how the framework could be used in practice. As mentioned above, many refinements are possible, and indeed warranted.

Table 1 shows the one-year transition matrix, which summarizes the probability for a borrower with a certain rating to move to a different rating over the next year.

Table 1. Modified Transition Matrix

\begin{tabular}{|c|c|c|c|c|c|c|c|c|c|c|}
\hline & & Aaа & $\mathrm{Aa}$ & $\mathrm{A}$ & Baa & $\mathrm{Ba}$ & $\mathrm{B}$ & Caa & Default & Withdrawn \\
\hline & & \multicolumn{9}{|c|}{ (In percent) } \\
\hline \multirow{8}{*}{$\begin{array}{c}\text { From } \\
\text { rating: }\end{array}$} & & \multicolumn{9}{|c|}{ To rating: } \\
\hline & Aaа & 0.878 & 0.087 & 0.001 & 0.000 & 0.000 & 0.000 & 0.000 & 0.000 & 0.034 \\
\hline & $\mathrm{Aa}$ & 0.005 & 0.886 & 0.069 & 0.001 & 0.000 & 0.000 & 0.000 & 0.000 & 0.039 \\
\hline & A & 0.001 & 0.044 & 0.866 & 0.042 & 0.004 & 0.002 & 0.000 & 0.000 & 0.041 \\
\hline & Baа & 0.002 & 0.009 & 0.093 & 0.786 & 0.047 & 0.011 & 0.001 & 0.002 & 0.049 \\
\hline & $\mathrm{Ba}$ & 0.000 & 0.001 & 0.014 & 0.102 & 0.726 & 0.061 & 0.014 & 0.008 & 0.074 \\
\hline & B & 0.000 & 0.001 & 0.006 & 0.008 & 0.111 & 0.689 & 0.046 & 0.029 & 0.110 \\
\hline & Caa & 0.000 & 0.000 & 0.000 & 0.000 & 0.007 & 0.051 & 0.188 & 0.660 & 0.094 \\
\hline
\end{tabular}

Source: Moodys; average one-year ratings transition of financial institutions.

This matrix refers to financial institutions, but could be produced for sovereigns as well. It is used to proxy the creditworthiness - (1-q) in equation (5) — of each individual borrower in the calculation of the value of the guarantee that the Fund would extend through providing liquidity. Of particular interest are cases for which the rating is downgraded twice in one year, as this would reflect a serious deterioration in market confidence. For instance, (1-q) would be equal to 1.1 percent for a Baa borrower, that is, the probability of it being rated $\mathrm{B}$ by the end of the year.

Table 2 reports the value of the American put option embedded in the Fund liquidity provision for different values of a country's net external position-to-reserves ratio and the volatility of its capital flows. The liquidity guarantee is assumed to be issued for one year, that is, the maturity of the option is one year. The risk-free
Table 2. Value of put option 1/

\begin{tabular}{lr}
\hline For $\mathrm{d}=0.7 ; \sigma^{2}=10$ & 40.0 \\
For $\mathrm{d}=0.7 ; \sigma^{2}=30$ & 40.1 \\
For $\mathrm{d}=0.8 ; \sigma^{2}=10$ & 20.0 \\
For $\mathrm{d}=0.8 ; \sigma^{2}=30$ & 22.7 \\
For $\mathrm{d}=1 ; \sigma^{2}=10$ & 2.4 \\
For $\mathrm{d}=1 ; \sigma^{2}=30$ & 9.9 \\
\hline
\end{tabular}

1 / In percentage points; $\tau$ is one year and $r$ is the one-year US treasury bill rate. 
discount factor is proxied by the one-year US treasury bill rate. ${ }^{9}$

Finally, Table 3 reports the value of the liquidity insurance provided by the Fund in case of a reversal in market sentiments. It ranges from a few to over one hundred basis points, reflecting the borrower's credit and liquidity risks as well as its debt to reserves ratio. As expected, the value of the guarantee increases with the debt-to-reserves ratio, reserves volatility, while decreases with a country's ratings. For instance, the value of Fund liquidity for a Baarated country with about 70 percent of its short-

Table 3. Value of Fund liquidity 1/

\begin{tabular}{lcccccc}
\hline & \multicolumn{7}{c}{ Type of borrower } \\
\hline & Aaa & Aa & A & Baa & Ba & B \\
\hline For $\mathrm{d}=0.7 ; \sigma^{2}=10$ & 0.040 & 0.040 & 0.160 & 0.440 & 0.560 & 1.160 \\
For d=0.7; $\sigma^{2}=30$ & 0.040 & 0.040 & 0.160 & 0.441 & 0.561 & 1.162 \\
For $\mathrm{d}=0.8 ; \sigma^{2}=10$ & 0.020 & 0.020 & 0.080 & 0.220 & 0.280 & 0.580 \\
For $\mathrm{d}=0.8 ; \sigma^{2}=30$ & 0.023 & 0.023 & 0.091 & 0.250 & 0.318 & 0.658 \\
For $\mathrm{d}=1 ; \sigma^{2}=10$ & 0.002 & 0.002 & 0.010 & 0.027 & 0.034 & 0.071 \\
For $\mathrm{d}=1 ; \sigma^{2}=30$ & 0.010 & 0.010 & 0.039 & 0.109 & 0.138 & 0.286 \\
\hline
\end{tabular}

1 / In percentage points; $\tau$ is one year and $r$ is the one-year US treasury bill rate.

term debt by remaining maturity covered by reserves and capital flow volatility of about 10 percent would be about 44 basis points to be assessed at time of qualification.

\section{ConCLUSiON}

Although not formally enshrined in its articles of agreement, the Fund has often operated as the ultimate provider of international liquidity, most notably in the more recent capital account crises. Fund resources are available to its member countries for fees that vary according to the financing facility that is accessed. These fees would reflect: (i) the transaction costs associated with administering the facility; (ii) the opportunity cost incurred as a result of not having the funds available for alternative uses; (iii) the remuneration for those members who make the liquidity available; (iv) credit risk; and (v) the intrinsic value of the liquidity guarantee that the Fund provides to the borrower.

Current pricing policies try to capture these costs/risks/benefits, but not necessarily in a marketbased fashion. In particular, the margin and the surcharge that apply to the proposed RAL transparently assess neither the borrower's credit risk nor the insurance value of such liquidity instrument; moreover, they would do it only ex post, that is, once the purchase has been made.

This paper presents a market-based framework for pricing Fund liquidity assistance, including under the RAL, that accounts for the credit risk and the insurance involved in such operations. It underscores the benefits to the member country of being able to access liquidity when needed. It is based on the isomorphic correspondence between Fund liquidity and common stock put options. As a market-based framework, it provides the necessary economic incentives to the prospective borrower, while explicitly assessing the costs for the liquidity provider.

\footnotetext{
${ }^{9}$ The American put option is used in the simulation as it is the one that would most closely fit a situation in which, after qualification, a member could access Fund liquidity at any time over the lifespan of the instrument. This is indeed the setting under the RAL current proposal.
} 
To be sure, market-signaling issues would need to be dealt with, particularly in light of the principle of equality of treatment across the membership that is central to the Fund's mandate. To allay these important concerns, while assuming that the Fund should not differentiate risk across its membership, it is worth noting that asset prices may already fully reflect the risk assessment of a specific borrower in orderly functioning markets, which would be the case at the time a member is qualified for access to Fund liquidity. In these circumstances, the distinction between lower- and higher-risks would reflect public market information. Also, the use of summary indices to assess a member's creditworthiness could, in practice, blur differences across the membership. Finally, from a technical point of view, the put option is likely to be heavily in the money for the majority of the countries that would have an interest in qualifying for access to Fund liquidity, reflecting large obligations compared to available resources. In these cases, a country's risk, as assessed by the volatility of its resources, would have a negligible impact on the value of the put option, evening out, in practice, the premiums across countries.

Most of the information that is required to operate the framework is already available within the Fund as part of the work on vulnerabilities and crisis prevention, while the rest can be retrieved from the market to a various extent depending on a country's financial development. Moreover, the implementation of such a framework would be consistent with the objectives of the Medium Term Strategy and complementary to the various activities envisages therein.

The simulations presented in this paper are only illustrative. They show that the value of the liquidity guarantee provided by accessing Fund liquidity, including under the RAL, could range from a few to over one hundred basis points depending on the borrower's creditworthiness, the volatility of capital flows to the borrowing country, and the amount of funds that would be potentially needed to meet the borrower's external obligations. The cost of this liquidity guarantee, which incorporates both credit risk and the instrument's insurance value, would complement the current fee structure under a Fund arrangement in the calculation of the overall rate of charge. This fee covering the cost of the liquidity guarantee would be assessed upfront when a member country is qualified for access to Fund liquidity, while leaving the other fees to kick in if purchases are ever made. 


\section{REFERENCES}

Barone-Adesi, G. and R. E. Whaley (1987) "Efficient Analytic Approximation of American Option Values,” Journal of Finance, 42, 301-20.

Black, F. and M. Scholes (1973) “The Pricing of Options and Corporate Liabilities,” Journal of Political Economy, 81, 637-54.

International Monetary Fund (2006) "Consideration of a New Liquidity Instrument for Market Access Countries”, IMF, August 03, 2006, www.imf.org.

MacMillan, L. W. (1986) “Analytic Approximation for the American Put Option,” Advances in Futures and Options Research, 1, 119-39.

Rossi, M. (1995) “Pricing Intraday Credit in Real-Time Gross-Settlement Systems,” LSE Financial Markets Group Discussion Paper No.211, London School of Economics.

Rossi, M. (1998) Payment Systems in the Financial Markets, Macmillan Press, UK, and St. Martin's Press, USA. 